\title{
Facebook levels the playing field: Dyslexic students learning through digital literacies
}

\author{
Owen Barden* \\ Centre for Culture \& Disability Studies, Liverpool Hope University, Liverpool, UK
}

(Received 13 April 2012; final version received 16 January 2014)

\begin{abstract}
Dyslexia has an ambivalent relationship with learning technology. Any potential gains may be nullified if the technology is perceived to exacerbate stigma. This paper examines the use of an 'everyday' technology, Facebook, by a small group of sixth form students labelled as dyslexic. 'Levelling the playing field' is a phrase the participants used often when discussing what they wanted from learning technology. Because dyslexia usually is defined in terms of significant difficulties with literacy, we might reasonably anticipate that the participants would see Facebook as stigmatising rather than levelling the playing field, because of the very public literacy events that it demands. However, the data indicate that far from shying away from Facebook because of fear of their difficulties with literacy being exposed, the participants enthusiastically embraced it. The students saw Facebook as a desirable presence in their education, one that supported inclusion. For them, levelling the playing field with Facebook had five dimensions: keeping up to date and meeting deadlines; increased control over learning; developing metacognitive awareness; greater control over literacy process and demands; and being experts and helpers. The findings perhaps challenge some assumptions about dyslexia, literacy and learning, and may be of interest to teachers working with dyslexic students, or researchers studying learning in digitally mediated social networks.
\end{abstract}

Keywords: social networking; digital literacies; dyslexia; adolescent; inclusion

\section{Introduction}

Throughout its 115-year history, the discourse of dyslexia has been characterised by the psycho-medical language of 'deficits', 'weaknesses' and 'difficulties'. Any examination of Dyslexia, The Annals of Dyslexia, psychology and educational textbooks, teacher-training literature and so on will quickly demonstrate this to be the case. By adopting a perspective on dyslexia that takes into account the social model of disability and the affordances of digitally mediated social networks, this study sought to challenge that dominant discourse. Nowadays, much 'everyday' digital technology is sophisticated enough to offer ample opportunity for students to circumvent many of the learning and literacy problems associated with dyslexia (Lankshear and Knobel 2003). Facebook is one example. This article reports on a study of the use of Facebook as an educational resource by five dyslexic students at a Sixth Form College in north-west England. The primary aim was to examine the educational affordances of Facebook. Subsidiary questions were: What does the project reveal

*Corresponding author. Email: bardeno@hope.ac.uk 


\section{O. Barden}

about the students' motivation to learn through literacy? What does it reveal about their sense of identity? What pedagogical principles does their use of the social network evoke?

Far from shying away from Facebook because of fears around their difficulties with typographic literacy, the participants enthusiastically embraced it as a research tool, and as an arena for both critical and playful literacy learning (Barden 2012; Hunter-Carsch 2001; Veater, Plester, and Wood 2011). The findings perhaps challenge some assumptions about dyslexia, literacy and learning, and may be of interest to teachers and researchers working with dyslexic students, or studying learning in digitally mediated social networks.

\section{The nature of dyslexia}

Dyslexia is a specific learning difficulty which mainly affects the development of literacy and language related skills. It is likely to be present at birth and to be lifelong in its effects. It is characterised by difficulties with phonological processing, rapid naming, working memory, processing speed, and the automatic development of skills that may not match up to an individual's other cognitive abilities. It tends to be resistant to conventional teaching methods, but its effects can be mitigated by appropriately specific intervention, including the application of information technology and supportive counselling.

(BDA 2007)

Dyslexia remains a controversial topic. There is no consensus amongst experts on either a definition or exact aetiology of dyslexia (NIACE 2004). The current British Dyslexia Association definition of dyslexia quoted above (BDA 2007), whilst retaining the emphasis on phonological (speech-sound) processing and literacy of earlier incarnations, reflects the growing understanding of the broader cognitive effects of dyslexia by including reference to memory, information processing speed and automaticity. ${ }^{1}$ The fact that dyslexia is so hard to precisely define has led some people to question its usefulness as a category or concept (Elliott and Gibbs 2008). However, recent technological advances, particularly fMRI brain scans, have been used to assert a biological basis for dyslexia. They have led to a more detailed and nuanced insight into the role of temporal development, hemispherical symmetry and localised functions of the brain in a wide range of learning tasks (Brunswick et al. 1999; Fawcett and Nicolson 1992; Geschwind and Galaburda 1985; Hoeft et al. 2007; Leppanen et al. 1999; Reid 2009). They claim to show that people with dyslexia tend to use different parts of their brains for specific language functions compared to nondyslexics (Lyon, Shaywitz, and Shaywitz 2003). They have also suggested that people labelled as dyslexic have more symmetrical, evenly sized hemispheres whilst nondyslexics have asymmetrical brains with relatively small right hemispheres (Breznitz and Lebovitz 2008; Galaburda 1989; Larsen et al. 1990). These differences in brain structure have been hypothesised to derive from in-utero neuron migration (Galaburda 2005). This brain cell migration ultimately affects cognition and produces, subject to environmental influences, a range of observable behaviours in the domain of language skills, short-term memory and temporal processing (Olson 2002). For example, students labelled with dyslexia typically find curricular literacy demands challenging, are 'quick forgetters' and are disorganised, in part because they tend to inaccurately estimate how long tasks will take them. 
Numerous researchers report that the academic difficulties associated with dyslexia are often accompanied by a range of behavioural and social problems including stress, demotivation, low confidence and low self-esteem (Alexander-Passe 2006, 2007; Burden 2005, 2008; Daniel et al. 2006; Pollak 2005; Singer 2007). These secondary affective consequences of dyslexia derive from perceptions - those of teachers and parents, as well as the individual themselves - that somebody is underperforming in their education, relative to their apparent intellectual ability and the attainments of their peers. These perceptions themselves derive to an extent from deficit models of dyslexia,which tend to characterise dyslexia as a constellation of deficiencies, weaknesses and problems (Frith 1999, 2002; Morton and Frith 1995). Different models foreground different features of the constellation, most prominently phonological processing (Snowling 1998, 2000), working memory (Jeffries and Everatt 2004), the cerebellum and automatisation (Fawcett and Nicolson 1992; Nicolson and Fawcett 1999), magnocellular visual processing (Stein 2001; Stein and Walsh 1997), and combinations of these (Wolf and Bowers 1999). These models thus reinforce in all parties the view that dyslexia equates to a deficiency.

\section{Dyslexia and the social model of disability}

Recently the tide has begun to turn. The contention that dyslexia must carry some distinct evolutionary advantage to explain its prevalence and intergenerational persistence has gained more credence. For Ehardt (2008), that advantage is linked to skills that would be valuable, and are still privileged, in pre-literate societies. This argument resonates with the social model of disability. Adherents of the social model of disability (Mason and Reiser 1990; Shakespeare and Watson 1997) recognise and accept that human beings are diverse creations, and maintain that societies create and sustain the concept of disability through structures of thought and environment. According to this view, dyslexia can only exist in cultures that privilege literacy, like ours. Dyslexia is not merely influenced by environmental factors such as orthography: the socio-cultural environment creates dyslexia through dependence on the written word. It is not difficult to imagine cultures where the dominant mode of communication for education is (or was) song, say, or drawings. An Ancient Egyptian who could not decode hieroglyphs, for example, might have been labelled 'dyspictoric'. Such a label does not exist in our culture because alphabetic literacy is prized in education to a far greater extent than a facility for images. Our alphabet is less than 2,000 years old. Universal schooling is less than 200 years old. The social model of dyslexia thus accounts for the fact that reading and writing are (in evolutionary terms) recently invented, unnatural processes that are difficult to learn for a large minority of the population. Extrinsic cultural forces have constructed the difficulty (McDermott and Varenne 1995), not the neurology of the individuals in the minority. This minority is labelled 'dyslexic', but the label is a product of the cultural privileging of reading and writing over a very short time span (Kress 2000).

\section{Digital technologies, adolescence and dyslexia}

Technology has long been seen as a solution for many of the problems associated with dyslexia. Microcassette dictaphones, followed by pocket spellcheckers, digital scanners, speech-to-text and text-to-speech software, reading pens and a whole host of others have all found followers. These technologies have in common a compensatory 


\section{O. Barden}

nature, at least in the way that students labelled with dyslexia are expected to use them. Often they are seen as 'special' solutions to a specific problem; this is reflected in the way Information and Communication Technology (ICT) is referred to as something to be 'applied' in the BDA definition of dyslexia with which I opened my introduction. The traditional view tends to see ICT as a way for people labelled with dyslexia to overcome obstacles (Smythe 2010), rather than providing opportunities for them to play to their cognitive strengths (West 2009). Commercial interests have also played their part in promoting ICT as a sort of 'silver bullet' for dyslexia. Dyslexic students are thus conceived of as part of the $\mathrm{SEN}^{2}$ group of learners who could potentially most benefit from digital inclusion (Walker and Logan 2009). However, 'special' solutions can exacerbate the stigma of dyslexia and cause resentment and reluctance to engage with learning-enhancing technology (Seale, Draffan, and Wald 2008). Now though, much 'everyday' digital technology offers ample opportunity for students to circumvent many of the learning and literacy problems associated with dyslexia. We can readily imagine a teenage student sitting in her bedroom, logged onto a social networking site, chatting with friends about the best way to complete her homework, whilst at the same time making plans to meet up when it's done. The student is dyslexic, but this isn't important because evryl use txtspk \& spllngs dnt mata. Her word processor will help 'correct' her spelling so that the assignment is acceptable to her teacher. A naturally visual thinker (West 2009), she is adept at the visual semantics and grammar the digital environment demands (Kress 2010; Kress and van Leeuwen 1996), and if necessary, for her work say, she can SMS, instant message, phone or video call a friend (Lankshear and Knobel 2003). She can consult YouTube or her institution's Virtual Learning Environment for audio-visual presentations of the current topic. All of this is commonplace, everyday routine technology use.

This scenario is not mere speculation. Empirical evidence already exists that digital social networks can boost academic self-esteem (Ellison, Steinfeld, and Lampe 2007) as well as literacy engagement and skills (Hughes et al. 2011; Veater, Plester, and Wood 2011; see also Crystal 2008). Positive reframing of dyslexic selves as successful learners can result (Gerber, Reiff, and Ginsberg 1996; Tanner 2010). Such evidence suggests that pedagogical potential resides within digitally mediated social networks. The study reported here contributes to this growing research field, and illustrates the participants' perceptions of Facebook as an inclusive educational resource.

\section{Research site and context}

\section{The college}

The research site is a large, highly successful Sixth Form College in north-west England. The institution has a strong ICT focus. The organisation is well-resourced in this regard, although devices such as mobile phones are usually restricted or prohibited on College premises. Facebook is barred on the College network but the participants and I were granted exclusive access for the duration of this study. Some participants reported accessing the site via their mobile phones whilst at College anyway, and questioned the worth of the embargo. This is something the organisation is aware of, but it has not yet decided how to deal with it.

Around 60 students per year identified as dyslexic have a weekly small-group study skills 'workshop' added to their timetable as part of a more comprehensive 
Additional Support Plan. A range of assistive hardware and software is available, but most do not make use of these even when taught how. This pattern challenges the perception that specialist technological solutions are necessary or desirable, at least for this sort of academically orientated adolescent learner. When asked in initial interviews, the participants said that they saw a place for specialist assistive technologies, but principally for younger or less able students. This could be interpreted as supporting the view that 'special' solutions can exacerbate the stigma of dyslexia, as noted above.

My preliminary survey of students in dyslexia workshops showed that, when engaged in scholarly activity, ICT is appreciated because it provides quick access to information and helps them produce a better standard of work more efficiently. For example, students value features such as the spellcheck in Microsoft Word. The emphasis on improving spelling, presentation and speed of working suggests that at least some of these students fit the picture painted by Lankshear and Knobel (2003): They are using everyday technology to circumvent problems of literacy, which for them are a product of dyslexia. ICT also motivates a high proportion of respondents towards engaging in practices that demand and encourage literacy, despite them being members of a group that has traditionally been marginalised by school literacies (LeCourt 2001; Ofsted 2009; Passey et al. 2004). Facebook is the most popular social network site amongst the students. Building a Facebook page and communicating with peers through it requires encoding, decoding, interpreting and analysing text, often whilst simultaneously 'dealing with' several conversations (Lewis and Fabos 2005). It also requires a degree of procedural knowledge - to 'learn all the links and what's where and such' as one participant said - to create digital artefacts that work to support social knowledge construction and hence learning (Lankshear and Knobel 2003), and to reinforce extended friendship networks (Ellison, Steinfeld, and Lampe 2007; Green and Hannon 2007).

\section{Facebook}

Facebook is an online social network. It is immensely popular, with approximately 1.3 billion monthly users worldwide (statisticbrain.com 2014). At the time of the study, the UK had the second largest number of users worldwide at 29.8 million, or $58 \%$ of the 54.1 million people online (Arthur 2011). Social network sites enable users to construct profiles based on personal information they are prepared to share, and to link with other users. They generally help users maintain existing networks; their unique feature is the way they make visible connections that would otherwise be invisible (Boyd and Ellison 2007). Use of social network sites is one of the most popular everyday activities on the World Wide Web (Stirling 2011). Facebook has been associated with students since its inception by Harvard undergraduates in 2003 (Kirkpatrick 2011). Facebook enables users to post 'status updates', short statements of current thoughts or activities. They can also upload files including photographs, videos and written documents. Hyperlinks can also be shared. Users can also send email-like messages to one another and chat in real time. The average user has around 130 Facebook 'friends' and spends almost an hour a day on the site (Kirkpatrick 2011). US college students spend on average over 100 minutes a day on Facebook (Kessler 2011). It thus has a significant presence in the day-to-day lives of many students, including my participants. 


\section{O. Barden}

\section{Methodology and methods}

Through a project in which teacher-researcher and student-participants co-constructed a Facebook group page about the students' scaffolded research into dyslexia, this study examined the educational affordances of a digitally mediated social network. An innovative methodology was devised, combining aspects of case study and action research with an ethnographic sensibility (Green and Bloome 1996). Thus, although the study could not be classified as 'an ethnography' it bore the hallmarks of ethnographic research: a participant-observer collecting rich field notes through intensive observation, and revisiting those notes to analyse them as data (White, Drew, and Hay 2009).

I employed a design premised on 'scaffolded co-construction' (Lankshear and Knobel 2003, p. 180) with my participants, using ICT to complete a negotiated educational task. The task was to construct a group Facebook page over five 90 -minute weekly sessions, recording the students' largely self-directed research into dyslexia. Scaffolding consisted of instigating and guiding the early activities, including suggesting the group develop their own ground-rules for posting to the page and interacting online with others, posting some links to help start the page, and offering a choice of research questions for the students to investigate. After that, my role was as participant-observer, documenting activity, acting as a knowledge and information source when requested, and monitoring the literacy and learning practices of the participants. The students thus collaboratively constructed their group Facebook page, working largely independently after initial guidance from me.

The methodology devised for this study is discussed extensively elsewhere (Barden 2013). Suffice to say here that it permitted multiple data collection methods including participant-observation, semi-structured pre- and post-project interviews, video, dynamic screen capture (Asselin and Moayeri 2010; Cox 2007) and protocol analysis (Ericsson and Simon 1993). This range of methods helped to capture much of the 'connected complexity' (Davies 2012) of the students' online and offline interactions with each other and with Facebook. For example, dynamic screen capture involved recording as a movie file everything that happened on a participant's screen during selected sessions. Combining such recordings with whole-classroom video recording helped reveal in fine detail individual participants' on-screen activities, and how these might prompt off-screen conversation or movement around the classroom to share new knowledge. Protocol analysis, which involved obtaining retrospective verbal reports in which the participants explained their recorded on-screen actions and concomitant thought processes, added another dimension to the data. Thus, the combination of methods helped to capture in detail multiple perspectives on the learning that happened in the classroom over the 5 weeks of the research project's lifetime. Even within this short period the volume and variety of data generated was sufficient to render a richly detailed picture of what went on in the classroom and hence reliably indicate the educational affordances of Facebook. The data presented here are drawn from over 70,000 words of transcript derived from these methods. In turn, this copious rich data was meticulously and comprehensively analysed using the rigorous reflexive methods advocated for constructing grounded theory (Charmaz 2006). Such analysis entails initial open coding of all verbal and visual data. Open coding is followed by multiple further iterations of coding and ipsative conceptual and thematic analysis. From the analysis a credible interpretation and explanation of what has been observed is constructed from the data. Silverman (2006) argues that collecting and analysing multiple sources of data in this way adds rigour, depth and 
complexity. Using multiple sources thus supported the study's aim of deducing effects on and principles of learning through literacy in a digitally mediated social network: establishing what the participants did in the network, and why they did things the way they did.

\section{Recruitment, sampling and ethics}

At the time of the study I was an established part-time specialist dyslexia tutor at the College. The Senior Management Team approved the project, with the proviso that it should ultimately aim to contribute to the curriculum. The five participants represent a sample of convenience: had I not been doing this research, I would have taught them anyway. A mixture of year groups and academic programmes was represented. The participants professed interest in the project, and represented a range of experiences and knowledge of dyslexia. They expressed a range of experiences, attitudes towards and purposes for online social networking. As A-level students and thus relatively high achieving academically, the sample is not representative of the population as whole. As dyslexics, they represent a minority within a minority. This must be taken into account when evaluating the findings.

Some students participating were under 18 years old. All were legally classified as disabled. Both these factors mark them out as potentially vulnerable and high-risk, but I could not conceive any serious risk or harm arising from the study. On the contrary, I thought that participating was something they would enjoy and benefit from. However, before starting I warned the students that people might post hostile comments on their Facebook page. They were still unanimous in wanting to use the project as a vehicle for promoting better understanding of dyslexia amongst their peers, and so were willing to accept the risk. In the ground-rules they devised for themselves, they pledged not to retaliate to any such comments. All students gave informed consent for confidential audio and video recordings to be made. I used a dedicated Facebook profile for myself, isolated from my personal one, to maintain my professional identity. The students used their existing personal profiles, and this did precipitate one significant ethical issue. By signing up to the Facebook group, the students automatically gave me access to their personal Facebook pages and profiles. Had I chosen to, I would have been able to look at status updates, photographs, and so on, which were unrelated to the project. I warned the participants of this. I had to make sure to only access the group page and not participants' individual ones. This is a concern that other researchers in similar contexts would also need to address.

\section{Data analysis and discussion}

'Levelling the playing field' is a phrase that came up often in the interviews I conducted with the participants, and also in the group discussions we had about what we wanted the project to achieve. I did not introduce the phrase at any point: it came from the students. Although it could be criticised as a cliché, it was evidently a concept that was important to the group. There were many small illustrations of Levelling the Playing Field littered throughout the data, and I present here selected examples that demonstrate the potential for Facebook to level the playing field.

Students identified as dyslexic are quite justified in seeing the field on which formal education is conducted as uneven, bumpy and tilted against them, such that they find themselves playing a game strewn with vexatious obstacles. To use an 


\section{O. Barden}

analogy from amateur football, they always seem to be the ones 'kicking uphill'. The traditional, autonomous view of literacy (Street 1984), which characterises literacy as a set of skills, rules and conventions to be internalised and applied by the individual, dominates education. Students labelled with dyslexia typically find these skills very challenging and are much less likely to master them than their peers. In an education system that has and continues to privilege alphabetic literacy, it is not surprising that these students can feel very strongly that they are not playing on a level field.

The students felt that ICT, digital media and Facebook could go a considerable way towards redressing these injustices and hence levelling the playing field. Whilst they all saw continued need for 'specialist' support for dyslexia that used ICT, they also saw mainstream ICT as having a role in redressing the imbalance. My interpretation of the students' words and actions over the course of this project is that for them, Levelling the Playing Field had the following five dimensions:

- Keeping up to date and meeting deadlines

- Increased control over when, where and how (by what mode) learning happens

- Developing metacognitive awareness of one's own learning preferences and processes

- Developing awareness of, and taking increasing control over, literacy processes and demands

- Giving and getting help on demand

\section{Keeping up to date and meeting deadlines}

The participants saw Facebook as a place where they could get all the information and help they needed, in one place, when they needed it. Independently in their interviews, they envisioned each class or subject in the College having its own Facebook page. This page would have all the necessary teaching and learning resources needed for the course. Each student taking that subject would be a Facebook friend of that subject group. Because students are 'always on Facebook', the perception was that, at any given time, someone would be available to answer queries - about deadlines, say or offer help. My participants saw this help as potentially being offered in two ways. Firstly, by the direct answering of relatively simple queries; an example might be 'What have we got to do for this week's Law homework?' They saw things operating differently in the second circumstance: when they were truly 'stuck' on something and needed more in-depth help. In this situation they anticipated using Facebook to quickly arrange to meet to get help face-to-face, either with a fellow student or teacher (much more reluctantly and much less likely). As well as its perceived ubiquity, this affordance of Facebook derives from its facility to sediment, and hence 'remember' conversations. Here is an excerpt from Josh's pre-project interview that illustrates this use of Facebook:

\section{Like I said before I'm extremely forgetful}

Josh: I mainly use it to look for people's birthdays because I'm extremely forgetful OB: Ok, what else do you use it for apart from ...

Josh: Well occasionally if I'm stuck on a piece of homework which I tend to be because I forget about it I use it to contact people in the class because I've got quite a few of my classmates on there. In fact I used it recently to do a Sociology essay.

OB: Tell me more about that. 
Josh: Er well it was over the holidays and er I didn't write the title down and one of my friends emailed me about it asking for help because she's not very strong at Sociology and I got the question off her and I did it myself and then I messaged her with things she could put in it and helped her out with that.

OB: Right ok you messaged on Facebook. So you use it mainly to help with birthdays but occasionally to help with work and you would chat about work on it.

Josh: Yeah.

OB: Ok. How much of your time d'ya reckon on Facebook would be spent doing stuff that's related to College work?

Josh: Well I probably would have said about $50 \%$ of it was asking about work. Like I said before I'm extremely forgetful and I need to ask people if we've got any homework ... I don't have the time for it $\{$ Facebook\} but if I ever need to I make sure I definitely get on it.

OB: What counts as need?

Josh: Like for homework

OB: Yeah there's lots of ways you could ask for help with homework you could ring people up you could go round to their house you could text them what makes you use Facebook for it?

Josh: Er its very easily accessible and most people my age are on it like all the time so and I think the layout's quite good as well like when you're messaging you can see what you put to them and its quite easy to understand what the work is if they're telling you about it.

OB: So what is it about the layout that's good?

Josh: It's ... you can see what you've put and then you can see what they've put and you can just you can see like your wall-to-wall and you can see what you've been talking to each other about and so rather than looking at what their answer and then going away and looking at what you've posted to them

OB: So you get that accumulation ...

Josh: Yeah

OB: ... and you can trace the history of what you've said

Josh: Yeah

These comments show Josh using Facebook as a sort of 'distributed memory' (Sparrow, Liu, and Wegner 2011), which stores not only deadlines but also conversations and hence thinking processes. This is significant given that problems with memory, organisation and sequentially ordering thoughts are common in dyslexia (Olson 2002). The comments also provide evidence that the students privileged the student perspective on learning. In line with current thinking about Web 2.0 epistemology (Dede 2008; Kress 2010), they seemed to subscribe to a social-constructivist conception of knowledge. This is a worldview that sees knowledge as co-constructed and held collectively, rather than individually. They appeared to value opportunities to learn with and from peers, rather than simply being told by a teacher, or being given prescriptive reading or writing tasks like filling in handouts and workbooks. Learning in this way was seen as more accessible, relevant and 'down to earth' than teacher-led classroom instruction. This peer-learning could take place in two principal ways: through each other's posts on Facebook, as described here, and through face-to-face discussion. The ways in which they responded to each other's posts, as Josh does here, provided evidence that the students could 'teach' each other through Facebook.

\section{Increased control over when, where and how learning happens}

Facebook is a multimodal virtual space. Students have access to it on their mobile devices, home computers and - sometimes - school or College computers. Teachers 


\section{O. Barden}

and peers can post links and other learning resources. Students can choose which resources to use, when and how often. They can also choose which to ignore or reject. Such choice is not merely a matter of convenience. It has some potentially profound impacts for students who find alphabetic literacy challenging. Instead of having to read through dense handouts or verbose textbooks to 'get at' detailed knowledge about a topic, students can simply search for and watch a video. If they don't understand, they can watch it, or parts of it, again - as many times as they like. The crucial thing for a dyslexic student is that they can attend to the visual and auditory modes - watching and listening (the modes where they are most likely to have cognitive strengths) without having to concentrate on the decoding of printed words and sentences (the mode they are most likely to find challenging). This implies faster learning, and learning in a way the student prefers and has control over. The memory challenge (Jeffries and Everatt 2004) may persist, but digital media offer two affordances to counteract this: the video can be watched again, as often as needed; or the video can be embedded or linked to on a Facebook page so that it has persistent presence on the relevant page, meaning the student can come back to it again at some point in the future if they need to. In other words, Facebook can 'remember' the video on the student's behalf (Sparrow, Liu, and Wegner 2011). They can then watch it again from almost any location, not just the classroom: Charlotte, for example, reported watching a documentary on the dyslexic actress Kara Tointon, to which I had posted a link on the group page. She watched it first in the classroom during one of the project sessions and then again at home with her family, partly for her own understanding and partly as a means of them developing shared understanding of dyslexia and Charlotte's experience of it. Charlotte's use of video to take control resonates with Chloe's, as described below in relation to fish oil supplements.

Chloe encountered a video on a Web site I had linked to on the group Facebook page. The video was of Professor John Stein of Oxford University, talking about the beneficial effects of fish oils on the brain and hence learning. My observational and screen-capture data confirmed that in one session, Chloe watched the 7-minute video twice. This gives an indication of motivation, significance of the topic, and perhaps a learning preference: watching before reading. She then read some of the comments on the page Stein's video was embedded in. After that she looked at some other reputable dyslexia research Web sites for corroboration. The data showed that within the space of 45 minutes, Chloe was able to quickly access and evaluate information on a topic of interest from an expert who normally publishes in textbooks and academic journals, and whose knowledge would, therefore, usually be inaccessible to a dyslexic A-Level student. In her post-project interview, Chloe said that she was happy to 'get really nerdy' and engage with texts relating to dyslexia and reading that she would otherwise have dismissed as 'too sciencey'. These comments reveal Chloe's developing sense of agency as a researcher, scientist and capable learner, and hence her diminishing sense of inferiority (Gerber, Reiff, and Ginsberg 1996; Tanner 2010).

\section{Developing metacognitive awareness of one's own learning preferences and processes}

Linked to controlling when, where and how learning happens is the idea that students can develop their metacognitive awareness through a multimodal environment like Facebook. Metacognition means 'thinking about thinking' It involves being aware of, and able to control, one's thinking and learning processes. The literature suggests that people labelled with dyslexia tend not to spontaneously develop good 
metacognitive awareness (McLoughlin, Leather, and Stringer 2002; Reid 2009). Finding ways of improving metacognitive awareness has therefore long been a staple of the specialist literacy and study-skills teaching interventions usually advocated for people identified as dyslexic. Emerging evidence from neuroscience also suggests that, in any learner (dyslexic or not), fostering understanding of the brain and how learning happens has the potential to do more to improve future learning than simply teaching study skills (Hinds 2010; Royal Society 2011).

There was evidence in this study that the students' self-directed learning was influenced by their learning preferences, and later altered and - according to the students' testimony - improved by their enhanced metacognitive knowledge. Here, for example, is Mohammed in his post-project interview, talking about his changing approach to reading and revision:

... before that I thought I was normal

Mohammed: I er just found out when I come here six months before that I thought I was normal like other people but I did have difficulty reading ... when I came here and when you did that test on me ... it was a shock to me I don't know that this happens but I didn't know nothing about dyslexia but when I come to this group then I start finding out information about dyslexia and how it affects people ...

OB: Erm so you've learnt a fair bit then ... has what you've learnt or has participating in the group changed the way you feel about dyslexia at all?

Mohammed: Yeah ... Yeah I do I feel I different now because before I used to like didn’t used to like \{unintelligible\} revising like reading I just used to like read the page and then just write cover that up and write again but when I come here after that I changed my method of to revising I used to like just skip on my reading so and then put it on mind maps or like structure the notes I have differently than I used to do before and I think it's changed the way I revise now

OB: Okay and what has what has prompted you to make those changes? Was it for instance things that you learnt from the page things you learnt from the group or was anything else?

Mohammed: No it was the things I learnt from the group and what you told us as well about how to revise from mind maps and all that

OB: So it was it was a mixture of partly things I taught you and things you found out on here is that ... fair to say?

Mohammed: Yeah

Mohammed had only recently been identified as dyslexic when he joined the group. Because he had previously seen himself as 'normal' he had revised in what he considered the 'normal' way, repeatedly reading his original notes and then covering them to test himself. Mohammed's account shows how, in combination with the feedback from the dyslexia assessment itself, and direct instruction in revision techniques, he was able to use resources provided by his fellow students to develop better awareness of what would make learning more effective for him, and hence take greater control over revision. Revision is a major component of curricular learning for students sitting exam-intensive A-Levels, so having greater control over it is very significant.

\section{Developing awareness of, and taking increasing control over, literacy processes and demands}

My participants were acutely and surprisingly aware of the processes and nature of reading and writing. This awareness of literacy demands is a crucial component in developing critical literacy (Davies and Merchant 2009) and critical digital literacies 


\section{O. Barden}

(Facer 2011). Their understanding, and the enthusiasm they showed for the topic, could be capitalised on to further develop critical literacy in the participants. This might include, for example, more explicit consideration of the affordances of the various modes Facebook puts at their disposal. Here I describe some of the ways in which students showed they were able to take greater control of literacy processes and demands.

Few would deny that it is difficult to learn well if we are physically uncomfortable. Yet students identified as dyslexic are often faced with persistent debilitating discomfort when they try to read and write. Chloe and Josh talked about the visual discomfort they experienced when reading; Mohammed described how his eyes would water if he tried to read for very long; Charlotte talked about the pain she got in her wrists when trying to write with a pen, even a specially designed ergonomic one. Digital media can level the playing field somewhat by giving students control over how they read and write, in such a way as to eliminate these discomforts. Chloe was able to change the background colour on her PC from white to peach, to enable her to read in comfort. Charlotte said that she could send 'thousands' of texts or type on a computer keyboard with no difficulty, ever. At a very basic level, the students thus valued digital media, including Facebook, for the way they enabled them to participate in comfort in reading and writing.

Moreover, removing the discomfort associated with reading and writing allows students to focus on the quality of the text, rather than struggling to engage with it at all. This further levels the playing field. Like any diligent students, my participants were keen to produce 'good' work for their College assignments and the contributions they made to the project: well-presented, with 'the right' facts, 'proper' spelling, and correctly deployed vocabulary. The students' perception was that the editing affordances of digital media, and the facility to ask for and get help, either from the peers or from the teacher, combined with the elimination of discomfort, was another way in which the playing field of literacy could be levelled.

A third way in which students took control of literacy processes was by engaging tactically with reading and writing (Williams 2011). Digital media help to level the playing field, but they do not flatten it completely. Reading and writing still present significant challenges, even with digital media tools. In addition to attending to individual texts tactically and selectively, the variety of texts available to students online helps them to select reading that they feel has the right content and is at the right level for them, without necessarily relying on a teacher to select for them. This is important, because in selecting a text based on the anticipated reading ability of a whole class, a teacher is likely to choose a text that a dyslexic student will find inaccessible or demoralising. However, the nature of my participants' on-screen activity was often characterised by fairly rapid switching between different windows, cycling in quick succession through a range of information sources. The students' observed behaviour, and their interview responses, indicates that they were happy to read or write tactically in order to gain or produce a summary of their learning. But they would tend to privilege other modes - video, or discussion with a peer, most likely - for getting the detail of a topic. In this way, they orchestrated and interpreted multimodal ensembles to communicate or construct meaning (Kress 2010). They were able to take control by foregrounding information presented in particular modes, according to personal preferences and the affordances of mode, in order to construct and disseminate knowledge. 
Taking control in this way is significant because it is an aspect of critical literacy. Critical literacy has received scant attention in the literature on specialist tuition for people labelled with dyslexia (Hunter-Carsch 2001), which has focussed almost exclusively on 'skills and drills'. Yet all students need to develop critical literacy, including awareness of the affordances of different modes in an increasingly informationsaturated online world (Facer 2011; Gee 2007). The implication for pedagogy is to foster critical awareness of how to arrange and interpret multimodal texts. This is levelling the playing field by treating modes more equitably: students labelled with dyslexia are likely to have talents in some modes to complement talents of nondyslexics in alphabetic literacy (Ehardt 2008; West 2009).

\section{Being 'experts' and 'helpers'}

I detected a paradox in the student's discussions about themselves and dyslexia. When asked directly in their interviews, the students tended to try and give the impression that they 'weren't bothered' or didn't have 'strong feelings' about their own dyslexia, as these three examples illustrate:

I've never particularly been bothered by it

OB: So has it changed the way you feel about dyslexia?

Charlotte: Erm kind of but I've never I've never particularly been bothered by it ...

OB: ... has it changed the way you feel about dyslexia or about being dyslexic?

Chloe: Not really just like no I don't think it has I've always I've never had never had an issue with being dyslexic ... I never sort of had any major feelings towards it I still don't it's just something I have to deal with ...

OB: Like maybe people with dyslexia often feel like outsiders y'know slightly excluded or slightly different to people who are not dyslexic and may be this is a way of tryin to ... build a bridge if you see what I mean

Danny: Yeah but like it's never really affected me cos instead of focusing on like English which obviously my weakness is instead of focusin on that I've always focused on my strengths ...

Despite rejecting the idea that dyslexia had had any significant negative impact on their lives when I interviewed them, my participants did say and do things that showed they had been left feeling angry and frustrated when they didn't get the help they felt they needed and deserved from teachers earlier in their school careers. Their comments support the idea that these students felt the school and educational playing field had been, and continued to be, biased against them, with serious consequences for their learning. Their expressed desire to inform others about dyslexia and the potential help and support available also indicates that they recognised the disadvantages people with dyslexia face in the education system and wider world. The anger and frustration expressed towards their peers, teachers and former schools is at odds with the emotional disinterest they asserted in relation to their own dyslexia. Chloe's admission, for example, in her initial interview that the reading she had to do for Biology left her 'feeling down and defeatist ... to the point where I may as well just not bother' contrasts vividly with her claim here that 'I've never had never had an issue with being dyslexic ... I never sort of had any major feelings towards it I still don't'. Also, it is difficult to see why the group would be so keen to help others unless they felt the difficulties and challenges dyslexia presents were significant. The word 'help' was used very often, with the group keen to position themselves as 'helpers'. On the one hand, this enabled them to think of themselves as altruistic 


\section{O. Barden}

'experts' on the topic of dyslexia, by virtue of their lived experiences, augmented by their research and learning for the Facebook research project. In contrast to the sense of inferiority revealed by the conversations about alphabetic literacy, the project thus helped Level the Playing Field by conferring some authority on the participants (Gerber, Reiff, and Ginsberg 1996). On the other hand, in recognising and seeking to act on the need for 'help' for dyslexic people like themselves they belied their assertions that dyslexia was not a significant challenge in their lives, and exposed, tacitly or explicitly, further frustrations arising from perceived disadvantage and discrimination.

\section{Conclusions}

Despite its rich multimodality, Facebook is driven by reading and writing. An individual might choose to update their status by simply posting a photograph, video, or hyperlink, but will usually accompany it with some text. Their Facebook friends respond by writing text, and other people can also read the comment threads, and add to them with further writing if they wish. We might therefore reasonably anticipate that students labelled with dyslexia, which is normally defined and characterised through difficulties with literacy, would find Facebook problematic. The evidence from this study suggests that, contrary to any such expectation, the participants were very highly motivated to learn through literacy whilst using Facebook. Thus, the principle affordance of Facebook was that it provided an arena for active, critical learning about dyslexia, literacy and selves. The ubiquity of Facebook and its status as an everyday, rather than assistive, technology meant that the students saw it as levelling the educational playing field for them in five significant ways relevant to dyslexia. Facebook acted as a kind of outsourced memory, sedimenting conversations and helping the students keep up to date with their work and meet their deadlines. The group Facebook page acted as a pedagogic hub for a range of resources, which gave them increased control over their literacy and learning, allowing them to privilege their preferred modes and recruit understanding gained from these modes in understanding complex texts. Allied to this was growing metacognitive awareness and sense of agency. The students were thus able to reframe themselves as successful learners, experts and helpers. The students' approach to learning was profoundly social and collaborative. This approach is in tune with a constructivist epistemology, which sees knowledge as being provisional, distributed and collective. In this study, this constructivist sensibility was facilitated and motivated by Facebook's perceived ubiquity and ease of use, as well as the social imperative to maintain peer networks. This study provides evidence that, like most students labelled with dyslexia, my participants justifiably feel that much education entails an uphill battle for them. My interpretation of the data, and the students' own comments, suggest very strongly that digitally mediated social networks have the potential to level the playing field for such students and hence make education more equitable.

\section{Notes}

1. The process by which newly learnt skills become second-nature, or automatic.

2. Special Educational Needs. The label given to students deemed to have learning difficulties or disabilities perceived to require provision outside or in addition to mainstream classroom teaching. 


\section{References}

Alexander-Passe, N. (2006) 'How dyslexic teenagers cope: an investigation of self-esteem, coping and depression', Dyslexia, vol. 12, no. 4, pp. 256-275.

Alexander-Passe, N. (2007) 'Sources and manifestations of stress amongst school-aged dyslexics, compared with sibling controls', Dyslexia, vol. 14, no. 4, pp. 291-313.

Arthur, C. (2011) 'Has Facebook peaked? New drop in number of UK users', The Guardian, [online] Available at: http://www.guardian.co.uk/technology/2011/jun/13/has-facebookpeaked-drop-uk-users.

Asselin, M. \& Moayeri, M. (2010) 'New tools for new literacies research: an exploration of usability testing software', International Journal of Research \& Method in Education, vol. 33 , no. 1 , pp. $41-53$.

Barden, O. (2012) ' $\ldots$ if we were cavemen we'd be fine. Facebook as a catalyst for critical, multiliteracy learning by dyslexic sixth-form students', Literacy, vol. 46, no. 3, pp. 123-132. DOI: 10.1111/j.1741-4369.2012.00662.x.

Barden, O. (2013) 'New approaches for new media: moving towards a connected methodology', Qualitative Research Journal, vol. 13, no. 1, pp. 6-24. DOI: 10.1108/14439881311314496.

Boyd, D. M. \& Ellison, N. B. (2007) 'Social network sites: definition, history, and scholarship', Journal of Computer-Mediated Communication, vol. 13, no. 1, article 11 [online] Available at: http://jcmc.indiana.edu/voll3/issue1/boyd.ellison.html

Breznitz, Z. \& Lebovitz, L. (2008) 'Neurobiological correlates of dyslexia', Ch. 1, in Brain Research in Language, ed. Z. Breznitz, Springer, New York, pp. 7-50.

British Dyslexia Association (2007) BDA Definition of Dyslexia., [online] Available at: http:// www.bdadyslexia.org.uk/about-dyslexia/further-information/dyslexia-research-information-. html

Brunswick, N., McCrory, E., Price, C. J., Frith, C. D. \& Frith, U. (1999) 'Explicit and implicit processing of words and pseudowords by adult developmental dyslexics: a search for Wernicke's Wortschatz?', Brain, vol. 122, no. 10, pp. 1901-1917.

Burden, R. (2005) Dyslexia and the Self. The Search for a Dyslexic Identity, Whurr, London.

Burden, R. (2008) 'Is dyslexia necessarily associated with negative feelings of self-worth? A review and implications for future research', Dyslexia, vol. 14, no. 3, pp. 188-196.

Charmaz, K. (2006) Constructing Grounded Theory. A Practical Guide Through Qualitative Analysis, SAGE, London.

Cox, R. (2007) 'Technology-enhanced research: educational ICT systems as research instruments', Technology, Pedagogy and Education, vol. 16, no. 3, pp. 337-356.

Crystal, D. (2008) 'Texting', ELT Journal, vol. 62, no. 1, pp. 77-83.

Daniel, S. D., et al. (2006) 'Suicidality, school dropout and reading problems amongst adolescents', Journal of Learning Disabilities, vol. 39, no. 6, pp. 507-514.

Davies, J. (2012) 'Facework on Facebook as a new literacy practice', Computers \& Education, vol. 59, no. 1, pp. 19-29.

Davies, J. \& Merchant, G. (2009) 'Negotiating the blogosphere: educational possibilities', Ch.3 in Digital literacies. Social learning and classroom practices, eds. V. Carrington, \& M. Robinson, SAGE/UKLA, London, pp. 81-94.

Dede, C. (2008) 'A seismic shift in epistemology', EDUCAUSE Review, vol. 43, no. 3, pp. $80-81$.

Ehardt, K. (2008) 'Dyslexia not disorder', Dyslexia, vol. 15, no. 4, pp. 363-366.

Elliott, J. G. \& Gibbs, S. (2008) 'Does dyslexia exist?', Journal of Philosophy of Education, vol. 42, no. 3-4, pp. 475-491.

Ellison, N. B., Steinfeld, C. \& Lampe, C. (2007) 'The benefits of Facebook 'friends:' social capital and college students' use of online social network sites', Journal of ComputerMediated Communication, vol. 12, no. 4. pp. 1143-1168.

Ericsson, K. A. \& Simon, H. A. (1993) Protocol Analysis. Verbal Reports as Data, Revised edn, The MIT Press, Cambridge, MA.

Facer, K. (2011) Learning futures. Education, technology and social change, Routledge, Abingdon, Oxon.

Fawcett, A. J. \& Nicolson, R. I. (1992) 'Automatisation deficits in balance for dyslexic children', Perceptual and Motor Skills, vol. 75, pp. 507-529.

Frith, U. (2002) 'Resolving the paradoxes of dyslexia', in Dyslexia and Literacy, eds. G. Reid, \& J. Wearmouth, Wiley, Chichester, pp. 45-68. 


\section{O. Barden}

Frith, U. (1999) Paradoxes in the definition of dyslexia. Dyslexia 5, pp. 192-214.

Galaburda, A. M. (1989) 'Ordinary and extraordinary brain development: anatomical variation in developmental dyslexia', Annals of Dyslexia, vol. 39, no. 1, pp. 65-80.

Galaburda, A. M. (2005) 'Dyslexia - a molecular disorder of neuronal migration', Annals of Dyslexia, vol. 55, no. 2, pp. 151-165.

Gee, J. P. (2007). What Video Games have to Teach us About Learning and Literacy, Revised edn, Palgrave Macmillan, New York.

Gerber, P. J., Reiff, H. B. \& Ginsberg, R. (1996) 'Re-framing the learning disabilities experience', Journal of Learning Disabilities, vol. 29, no. 1, pp. 98-101.

Geschwind, N. \& Galaburda, A. M. (1985) 'Cerebral lateralization. Biological mechanisms, associations and pathology. I.A. Hypothesis and a program for research', Archives of Neurology, vol. 42, pp. 428-459.

Green, H. \& Hannon, C. (2007) Their Space. Education for a Digital Generation, Demos, London, England.

Green, J. \& Bloome, D. (1996) 'Ethnography and ethnographers of and in education: a situated perspective', in A Handbook for Literacy Educators: Research on Teaching the Communicative and Visual Arts, eds. J. Flood, S. Heath \& D. Lapp, Macmillan, New York, pp. $1-12$.

Hinds, D. (2010) 'Please sir, my brain hurts,' Times Educational Supplement [online] Available at: http://www.tes.co.uk/article.aspx?storycode $=6064899$

Hoeft, F., et al. (2007) 'Functional and morphometric brain dissociation between dyslexia and reading ability', Proceedings of the National Academy of Sciences of the United States of America, vol. 104, no. 10, pp. 4234-4239.

Hughes, J., Herrington, M., McDonald, T. \& Rhodes, A. (2011) 'E-portfolios and personalized learning: research in practice with two dyslexic learners in UK higher education', Dyslexia, vol. 17 , pp. $48-64$.

Hunter-Carsch, M. (2001) 'Preface: bridging the gap', in Dyslexia \& effective learning in secondary and tertiary education, eds. M. Hunter-Carsch \& M. Herrington, Whurr, London, pp xvii-xxv.

Jeffries, S. \& Everatt, J. (2004) 'Working memory: its role in dyslexia and other learning difficulties', Dyslexia, vol. 10, pp. 196-214.

Kessler, S. (2011) 'How students use technology', [online] Available at: http://mashable.com/ 2011/08/10/students-technology-infographic/

Kirkpatrick, D. (2011) The Facebook Effect, Virgin Books, London.

Kress, G. (2000) 'Multimodality', in Multiliteracies. Literacy Learning and the Design of Social Futures, eds. B. Cope \& M. Kalantzis, Routledge, Abingdon and New York, pp. 153-161.

Kress, G. (2010) Multimodality. A social semiotic approach to contemporary communication, Routledge, Abingdon, Oxon.

Kress, G. \& van Leeuwen, T. (1996) Reading Images. The Grammar of Visual Design, Routledge, London.

Lankshear, C. \& Knobel, M. (2003) New Literacies. Changing knowledge and classroom learning, Open University Press, Buckingham \& Philadelphia.

Larsen, J. P., Høien, T., Lundberg, I. \& Ødegaard, H. (1990) 'MRI evaluation of the size and symmetry of the planum temporale in adolescents with developmental dyslexia', Brain \& Language, vol. 39, no. 2, pp. 289-301.

LeCourt, D. (2001) 'Technology as material culture. A critical pedagogy of 'technical literacy", in ICT, pedagogy and the curriculum, eds. A. Loveless \& V. Ellis, Routledge-Falmer, London $\&$ New York.

Leppanen, P. H., Pihko, E., Eklund, K. M. \& Lyytinen, H. (1999) 'Cortical responses of infants with and without a genetic risk for dyslexia. II: group effects', Neuroreport, vol. 10, pp. 969-73.

Lewis, C. \& Fabos, B. (2005) 'Instant messaging, literacies, and social identities', Reading Research Quarterly, vol. 40, no. 4, pp. 470-501.

Lyon, R. G., Shaywitz, S. \& Shaywitz, B. (2003) 'Defining dyslexia, comorbidity; teacher's knowledge of language and reading', Annals of Dyslexia, vol. 53, pp. 1-14. 
Mason, M. \& Reiser, R. (1990) 'The medical model and the social model of disability', in Disability Equality in the Classroom: A Human Rights Issue, eds. M. Mason \& R. Reiser, London, Inner London Education Authority.

McDermott, R. \& Varenne, H. (1995) 'Culture 'as' disability', Anthropology \& Education Quarterly, vol. 26, no. 3, pp. 324-348.

McLoughlin, D., Leather, C. \& Stringer, P. (2002) The Adult Dyslexic. Interventions and Outcomes, Whurr, London.

Morton, J. \& Frith, U. (1995) 'Causal modelling: a structural approach to developmental psychopathology', in Manual of Developmental Psychopathology, eds. D. Cicchetti \& D. J. Cohen, John Wiley and Sons, New York, pp. 357-390.

NIACE. (2004) A Framework for Understanding Dyslexia, DFES, London.

Nicolson, R. I. \& Fawcett, A. J. (1999) 'Developmental dyslexia: the role of the cerebellum', Dyslexia, vol. 5, pp. 155-177.

Ofsted. (2009) The importance of ICT: information and communication technology in primary and secondary schools, 2005/2008, HMI, London.

Olson, R. K. (2002) 'Dyslexia: nature and nurture', Dyslexia, vol. 8, pp. 143-159.

Passey, D., Rogers, C., Machell, J. \& McHugh, G. (2004) The Motivational Effect of ICT on Pupils, DFES/ Lancaster University, Lancaster, England.

Pollak, D. (2005) Dyslexia, the Self and Higher Education, Trentham, Stoke on Trent.

Reid, G. (2009) Dyslexia: A Practitioner's Handbook, 4th edn, Wiley, Chichester.

Royal Society, The. (2011) Brain Waves Module 2: Neuroscience: Implications for Education and Lifelong Learning [online] Available at: http://royalsociety.org/uploadedFiles/Royal_Society/ Policy_and_Influence/Module_2_Neuroscience_Education_Full_Report_Appendices.pdf

Seale, J., Draffan, E. A. \& Wald, M. (2008) 'Exploring Disabled Learners' Experiences of Learning, LEXDIS Final Report to JISC, [online] Available at: http://www.lexdis.ecs. soton.ac.uk/project/media/LEXDIS_ProjectReport_Dec08final.doc

Shakespeare, T. \& Watson, N. (1997) 'Defending the social model of disability', Disability and Society, vol. 12, no. 2, pp. 293-300.

Silverman, D. (2006) Interpreting Qualitative Data. 3rd Edition. London: SAGE.

Singer, E. (2007) 'Coping with academic failure, a study of Dutch children with dyslexia', Dyslexia, vol. 13 , no. 4, pp. 313-333.

Smythe, I. (2010) Dyslexia in the Digital Age. Making IT work, Continuum, London.

Snowling, M. J. (1998) 'Dyslexia as a phonological deficit: evidence and implications', Child and Adolescent Mental Health, vol. 3, no. 1, pp. 4-11.

Snowling, M. J. (2000) Dyslexia, Blackwell, Oxford.

Sparrow, B., Liu, J. \& Wegner, D. M. (2011) 'Google effects on memory: cognitive consequences of having information at our fingertips', Science, [online] Available at: http:// www.sciencemag.org.eresources.shef.ac.uk/content/333/6040/277.summary

Statisticbrain.com (2014) 'Facebook statistics', [online] Available at: http://www.statisticbrain. com/facebook-statistics/

Stein, J. (2001) 'The magnocellular theory of developmental dyslexia', Dyslexia, vol. 7, no. 2, pp. $12-36$.

Stein, J. \& Walsh, V. (1997) 'To see but not to read: the magnocellular theory of dyslexia', Trends in Neurological Science, vol. 20, pp. 147-52.

Stirling, E. (2011) 'Facebook me ... I'll add you. Making sense of multi-sited ethnographic data', Paper presented at The Centre for the Study of New Literacies Annual Conference, University of Sheffield, 9 July 2011.

Street, B. (1984) Literacy in Theory and Practice, Cambridge University Press, Cambridge.

Tanner, K. (2010) 'Reframing dyslexia as a result of customised educational provision in an adult learning environment', Paper presented at the Inclusive and Supportive Education Congress, University of Belfast, August 2010.

Veater, H., Plester, B. \& Wood, C. (2011) 'Use of text message abbreviations and literacy skills in children with dyslexia', Dyslexia, vol. 17, no. 1, pp. 65-71.

Walker, L. \& Logan, A. (2009) Using Digital Technologies to Promote Inclusive Practices in Education, Futurelab, Bristol. 


\section{O. Barden}

West, T. G. (2009) The Mind's Eye. Creative Visual Thinkers, Gifted Dyslexics and the Rise of Visual Technologies, Prometheus, New York.

White, S., Drew, S. \& Hay, T. (2009) 'Ethnography versus case study. Positioning research and researchers', Qualitative Research Journal, vol. 9, no. 1, pp. 18-27.

Williams, B. T. (2011) 'The world on your screen: Literacy and popular culture in a networked world', Paper presented at The Centre for the Study of New Literacies Annual Conference, University of Sheffield, 8 July 2011.

Wolf, M. \& Bowers, P. G. (1999) 'The double-deficit hypothesis for the developmental dyslexias', Journal of Educational Psychology, vol. 91, pp. 415-438. 